\title{
Efeitos de Quantidades de Fitomassa de Adubos Verdes na Supressão de Plantas Daninhas ${ }^{1}$
}

\author{
Effects of Cover Crop Biomass Quantities on Weed Suppression \\ SEVERINO, F.J. ${ }^{2}$ e CHRISTOFFOLETI, P.J. ${ }^{3}$
}

\begin{abstract}
RESUMO - Com o objetivo de avaliar as correlações entre a utilização de diferentes quantidades de fitomassa, incorporada ou na superfície do solo, dos adubos verdes amendoim-forrageiro (Arachis pintoi), crotalária (Crotalariajuncea) e feijão-guandu-anão (Cajanus cajan) na redução da emergência e produção de fitomassa seca das plantas daninhas capim-braquiária (Brachiaria decumbens), capim-colonião (Panicum maximum) e picão-preto (Bidens pilosa), foi instalado um experimento em casa de vegetação do Departamento de Produção Vegetal da ESALQ/USP-Piracicaba. O delineamento experimental utilizado foi o de blocos casualizados, com os tratamentos em quatro repetições, em esquema fatorial $3 \times 6 \times 3 \times 2$, sendo três adubos verdes (A. pintoi, C. juncea e C. cajan), seis quantidades de fitomassa $(0 ; 0,5 ; 1 ; 2 ; 4$; e 8 vezes a quantidade de adubo verde produzido pela média de campo), três plantas daninhas (B. decumbens, P. maximum e B. pilosa) e duas formas de distribuição da fitomassa dos adubos verdes (na superfície do solo e de 0 a $5 \mathrm{~cm}$ de profundidade). As características avaliadas durante a condução do experimento foram as seguintes: densidade de plantas daninhas/ vaso e produção de fitomassa seca das plantas daninhas (g/vaso), determinadas aos 15 e aos 30 dias após a instalação do experimento. Os resultados permitiram concluir que a fitomassa dos adubos verdes, nas duas formas utilizadas, reduz significativamente as populações das plantas daninhas testadas. As correlações ocorrem de maneira distinta pelos diferentes adubos verdes, sendo o feijão-guandu-anão, de forma geral, o mais efetivo na supressão das plantas daninhas.
\end{abstract}

Palavras-chave: Arachis pintoi, Crotalaria juncea, Cajanus cajan, Brachiaria decumbens, Panicum maximum, Bidens pilosa.

\begin{abstract}
Different biomass quantities of the cover crops Arachis pintoi Krapov. \& W.C. Gregory, Crotalaria juncea and Cajanus cajan were either incorporated or spread on the surface of the soil to study their effect on the emergence and dry mass production of the weeds Brachiaria decumbens, Panicum maximum and Bidens pilosa. The experiment was installed in pots and conducted under greenhouse conditions at the Department of Plant Production of ESALQ - Universidade de São Paulo, Piracicaba-SP, Brazil. The experimental design consisted of a $3 \times 6 \times 3 \times 2$ factorial. i.e., three cover crops (A. pintoi, C. juncea and C. cajan), six amounts of cover crop mass, $0,0.5,1,2,4$, and 8 times the average biomass produced under field conditions, three weeds (B. decumbens, $\boldsymbol{P}$. maximum, B. pilosa) and two depths of cover crop residue incorporation $(O$ and $5 \mathrm{~cm}$ ). The parameters evaluated were: two weed counting/ pot, and weed dry mass yield (g/pot), at 15 and 30 days after the establishment of the experiment. Cover crop mass at the two depths of incorporation was shown to reduce the weed populations tested, although in different degrees of interference, with $\mathbf{C}$. cajan being, in general, the most effective in suppressing weeds.
\end{abstract}

Key words: Arachis pintoi, Crotalaria juncea, Cajanus cajan, Brachiaria decumbens, Panicum maximum, Bidens pilosa.

Recebido para publicação em 2/2/2001 e na forma revisada em 2/7/2001.

2 Eng.-Agro., M.S., Universidade de São Paulo, Escola Superior de Agricultura “Luiz de Queiroz”, área de concentração Fitotecnia. Av. Pádua Dias, 11 - Caixa Postal 09, 13418-900 Piracicaba-SP, bolsista da CAPES, <fjseveri@carpa.ciagri.usp.br>; ${ }^{3}$ Eng.Agr ${ }^{\circ}$, Ph.D., Professor Associado, Universidade de São Paulo, Escola Superior de Agricultura “Luiz de Queiroz", Departamento de Produção Vegetal, Av. Pádua Dias, 11 - Caixa Postal 09, 13418-900 Piracicaba-SP, <pjchrist@ carpa.ciagri.usp.br>.

Planta Daninha, Viçosa-MG, v.19, n.2, p.223-228, 2001 


\section{INTRODUÇÃO}

A adubação verde é uma prática agrícola conhecida desde a antiguidade e pode ser entendida como a incorporação ao solo de material vegetal não-decomposto, produzido ou não no local. A utilização desta técnica propicia alterações desejáveis no solo, melhorando as propriedades físicas, químicas e biológicas deste e proporcionando à cultura subseqüente benefícios que geralmente se refletem em ganhos de produtividade (Igue, 1984; Primavesi, 1986; Vogtmann \& Wagner, 1987; Bulisani et al., 1987; Piamonte, 1996; Coleman, 1995; Teasdale, 1998).

Embora a utilização da adubação verde tenha sido bastante pesquisada anteriormente e muitos dos benefícios produzidos pelo seu emprego sejam conhecidos, grande parte destes trabalhos não estabelece relações com o controle de plantas infestantes (Christoffoleti, 1988). No entanto, as plantas daninhas nocivas têm grande dificuldade em manter população em determinada área, quando esta prática agrícola é empregada (Walker \& Buchanan, 1982).

Dessa maneira, a fitomassa produzida pela adubação verde tem influência direta na supressão de plantas daninhas nos agroecossistemas, pois existe correlação linear entre a quantidade desta fitomassa e a efetiva redução da infestação por plantas daninhas, e diferentes espécies de adubos verdes modificam a composição da população das plantas daninhas infestantes na área (Almeida \& Rodrigues, 1985).

Também a cobertura morta altera as características físicas, químicas e biológicas do solo, modificando a constituição qualitativa e quantitativa do complexo florístico que se desenvolve nesse local, interferindo no processo de quebra de dormência das sementes e, devido à sua ação alelopática, na germinação e no desenvolvimento das plântulas (Almeida, 1991).

A alelopatia, segundo Molish (1937), é a introdução no ambiente de substâncias químicas elaboradas por algumas espécies da comunidade e que afetam o comportamento de outras. Os compostos químicos responsáveis pela alelopatia são denominados aleloquímicos. São elaborados pelas células com finalidades específicas, e uma única planta pode produzir centenas deles (Swain, 1977). Cada espécie produz um conjunto diferente de aleloquímicos, com ação diferenciada sobre os componentes da comunidade onde está inserida (Putnam \& Duke, 1974).

Em relação à luz, de acordo com Chancellor (1980 e 1982), sementes que possuem a proteína fitocromo (P), a qual governa o processo de dormência, na presença de raios vermelhos convertem-se em formas que ativam a germinação, e, na sua ausência, retornam à composição original, impedindo que germinem.

Entretanto, a água também é essencial ao processo de germinação, o qual somente se inicia quando a semente fica embebida, o que depende da permeabilidade do tegumento. Segundo Popey (1976), há espécies em que a permeabilidade só se verifica após longo tempo de contato da semente com a água; outras exigem alternâncias de alto e baixo teor de água no solo.

Também a temperatura exerce, notadamente, grande influência na quebra da dormência das sementes. O requisito de temperatura para que a germinação se inicie varia de espécie para espécie, como, por exemplo, espécies de verão e de inverno, enquanto outras necessitam que a temperatura sofra alternações diuturnas para que a germinação se inicie (Chancellor, 1982).

A prática da adubação verde, além dos benefícios normalmente citados, pode ser uma valiosa ferramenta no sistema de manejo integrado de plantas daninhas.

Assim, o objetivo do presente experimento foi avaliar a influência da quantidade de fitomassa de três espécies de leguminosas, aplicadas na superfície ou incorporadas ao solo, sobre a redução da infestação de plantas daninhas.

\section{MATERIAL E MÉTODOS}

A pesquisa foi realizada em casa de vegetação, na área experimental do Departamento de Produção Vegetal da Escola Superior de Agricultura "Luiz de Queiroz", campus da ESALQ/USP, em Piracicaba-SP.

O experimento foi instalado na segunda quinzena de dezembro de 1999. O solo foi 
coletado, com trado de $4,3 \mathrm{~cm}$ de diâmetro, na profundidade de $0-10 \mathrm{~cm}$, sendo as amostras colocadas em sacos plásticos, levadas para o laboratório e peneiradas (peneira com malha de $0,280 \mathrm{~mm}$ ). O local de coleta do solo foi de uma área ocupada por um pomar de abacate (Persea americana), em solo argiloso, com 38\% de argila, 19\% de silte e 43\% de areia, pH 5,3 e $37 \mathrm{~g} / \mathrm{dm}^{3}$ de matéria orgânica, que apresentava alta infestação natural de plantas daninhas, composta por mono e dicotiledôneas.

Nos vasos foram colocados $200 \mathrm{~cm}^{3} \mathrm{de}$ solo/vaso e 100 sementes de cada planta daninha, as quais foram pesadas e devidamente identificadas; as demais quantidades de sementes usadas foram, então, determinadas por pesagem. As plantas daninhas utilizadas foram capim-braquiária (B. decumbens), capim-colonião ( $P$. maximum) e picão-preto (B. pilosa), além da infestação natural da área experimental. Foi também realizada a coleta dos adubos verdes que já estavam plantados no experimento de campo - amendoim-forrageiro (A. pintoi), crotalária (C. juncea), feijãoguandu-anão (C. cajan) - e das plantas daninhas da área sem adubo verde. As parcelas de cada adubo verde foram subdivididas e nelas semeados capim-braquiária (B. decumbens), capim-colonião ( $P$. maximum) e picão-preto (B. pilosa), mais a infestação natural do terreno. A coleta dos adubos verdes foi feita medindo-se, com uma trena de 20 m, 3 metros lineares de cada adubo verde, que foram cortados (apenas a parte aérea), o que permitiu calcular o peso de cada um em hectare. Esse material foi colocado em sacos plásticos e levado para o laboratório, onde eram picados, pesados e devidamente identificados. O cálculo da quantidade de adubo verde utilizada por vaso baseou-se na produção média da massa verde da parte aérea em $t /$ ha dos adubos verdes obtida no experimento de campo, as quais foram: para Arachis pintoi, 6,45 t ha ${ }^{-1}$; para Crotalaria juncea, 17,64 t ha-1; e para Cajanus cajan, $14,32 \mathrm{t} \mathrm{ha}^{-1}$.

As quantidades utilizadas dos adubos verdes, tanto na superfície dos vasos como de forma incorporada ao solo dos vasos, foram as seguintes: $0 x, 0,5 x, 1 x, 2 x, 4 x$ e $8 x$, sendo $0 x$ a testemunha e $1 \mathrm{x}$ a quantidade calculada a partir do experimento de campo.
Quando se utilizaram os adubos verdes em cobertura, o solo foi colocado nos vasos, retirando-se os primeiros $5 \mathrm{~cm}$ de profundidade deste solo, que foram colocados num saco plástico, juntamente com as sementes de plantas daninhas, identificados e pesados. Em seguida, homogeneizou-se e colocou-se esse solo de volta nos vasos, naquela mesma camada, ou seja, nos primeiros $5 \mathrm{~cm}$. A seguir, foram colocados os adubos verdes triturados na superfície dos vasos, nas quantidades anteriormente mencionadas.

Guando foram utilizados os adubos verdes incorporados ao solo, este foi colocado nos vasos, retirando-se os primeiros $5 \mathrm{~cm}$ de profundidade deste solo, que foram colocados num saco plástico, juntamente com as sementes de plantas daninhas e com os adubos verdes já triturados. Após a homogeneização, este solo foi colocado de volta nos vasos na mesma camada, sendo estes submetidos a sistema de irrigação diária, composto por microaspersores, controlados por um "timer", irrigando aproximadamente $5 \mathrm{~mm}$ cada vez que era acionado. A temperatura, umidade relativa e luminosidade eram controladas automaticamente.

As características avaliadas durante a condução do experimento foram as seguintes: densidade de plantas daninhas/vaso e produção de fitomassa seca das plantas daninhas (g/vaso), determinadas aos 15 e aos 30 dias após a instalação do experimento.

No caso das avaliações, foi feita a contagem e o corte cuidadoso da parte aérea das plantas daninhas, que, em seguida, foram secadas e pesadas. O delineamento experimental utilizado foi o de blocos casualizados, com os tratamentos em quatro repetições, em esquema fatorial $3 \times 6 \times 3 \times 2$, sendo três adubos verdes (A. pintoi, C.juncea e C. cajan), seis quantidades de adubo verde $(0 \mathrm{x}, 0,5 \mathrm{x}, 1 \mathrm{x}, 2 \mathrm{x}, 4 \mathrm{x}$ e $8 \mathrm{x})$, três plantas daninhas $(B$. decumbens, $P$. maximum e B. pilosa) e duas profundidades de incorporação do adubo verde (na superfície do solo e a $5 \mathrm{~cm}$ de profundidade).

A análise de variância dos resultados foi realizada com o auxílio do Sistema de Análise Estatística - SANEST, e as médias foram submetidas ao teste de Tukey a $5 \%$ de probabilidade.

Planta Daninha, Viçosa-MG, v.19, n.2, p.223-228, 2001 


\section{RESULTADOS E DISCUSSÃO}

Nas Figuras 1 a 4 estão apresentadas as médias de densidade e de produção de biomassa seca das plantas daninhas, da primeira e da segunda avaliação, a partir de amostras retiradas dos diversos tratamentos aplicados no experimento na superfície do solo. É importante salientar que, quando foram utilizadas as leguminosas na superfície do solo, não houve diferenças significativas entre elas, isto é, todos os três adubos verdes testados causaram os mesmos efeitos na redução da densidade e da produção de biomassa seca das plantas daninhas em estudo. Assim, nos gráficos estão representados os dados médios dos três adubos verdes em conjunto (Figuras 1 a 4).

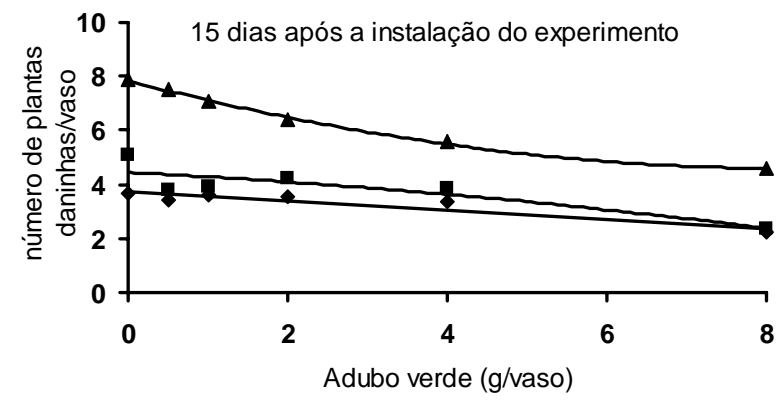
- Brachiaria decumbens
$R^{2}=0,875$
- Panicum maximum
$R^{2}=0,8376$
$\Delta$ Bidens pilosa
$R^{2}=0,9963$

Figura 1 - Número de plantas daninhas por vaso, em função de adubos verdes aplicados em cobertura no solo (Piracicaba, 2000).

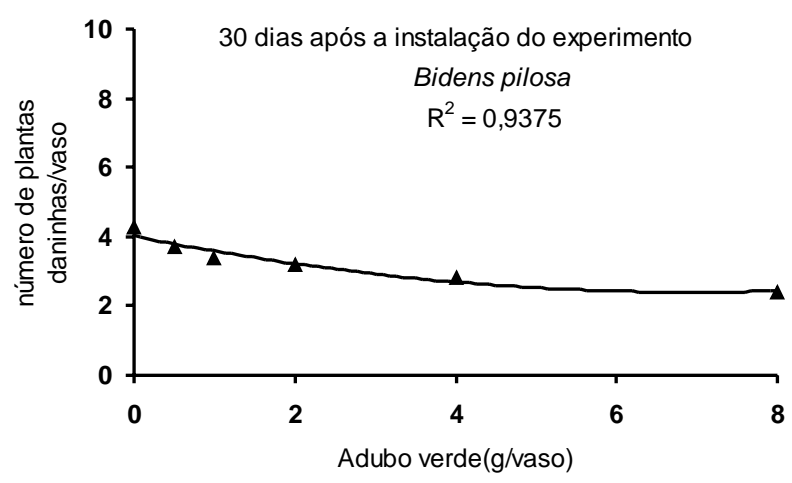

Figura 2 - Número de plantas daninhas por vaso, em função de adubos verdes aplicados em cobertura no solo (Piracicaba, 2000).

Planta Daninha, Viçosa-MG, v.19, n.2, p.223-228, 2001
Analisando as Figuras 1 e 3, observam-se interações entre a quantidade de adubo verde utilizada e a redução da densidade e da produção de biomassa seca das plantas daninhas, pois, à medida que se aumentou a quantidade de fitomassa do adubo verde, ocorreram, de forma geral, reduções nestas características de avaliação. Na Figura 3 verifica-se, ainda, que na quantidade $4 \mathrm{x}$ houve estímulo na produção de fitomassa seca de capim-colonião.

Nas Figuras 2 e 4 está representada a curva de resposta apenas da planta daninha picãopreto, uma vez que, aos 30 dias após, as demais plantas daninhas (capim-braquiária e capimcolonião) não foram afetadas na densidade nem na fitomassa seca em função das quantidades de adubos verdes, provavelmente por serem mais eficientes nas respostas às interferências.

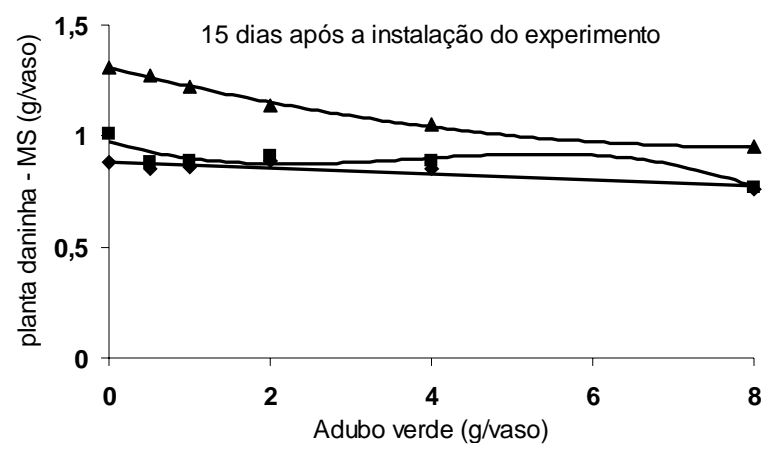

- Brachiaria decumbens $R^{2}=0,7558$

- Panicum maximum $\quad \mathrm{R}^{2}=0,8214$

\Bidens pilosa $\quad R^{2}=0,997$

Figura 3 - Biomassa seca de plantas daninhas por vaso, em função de adubos verdes aplicados em cobertura no solo (Piracicaba, 2000).

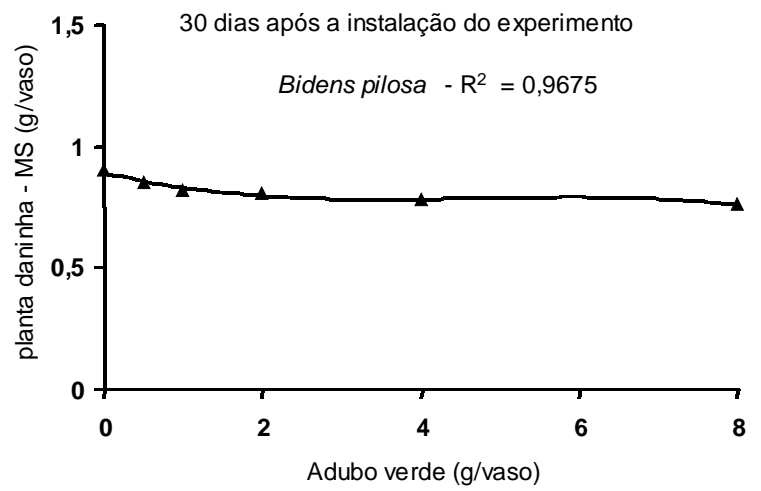

Figura 4 - Biomassa seca de plantas daninhas por vaso, em função de adubos verdes aplicados em cobertura no solo (Piracicaba, 2000). 
Nas Figuras 5 a 7 estão apresentadas as médias de densidade de plantas daninhas da primeira avaliação, quando se utilizou o adubo verde incorporado ao solo. Neste caso, houve diferenças significativas entre eles, isto é, os três adubos verdes causaram diferentes efeitos na redução da densidade das plantas daninhas.

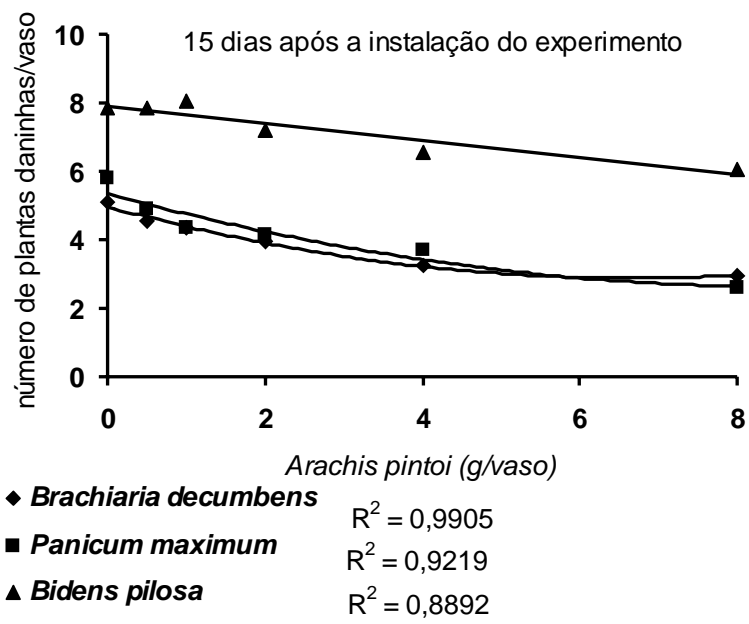

Figura 5 - Número de plantas daninhas por vaso, em função do adubo verde incorporado ao solo (Piracicaba, 2000).

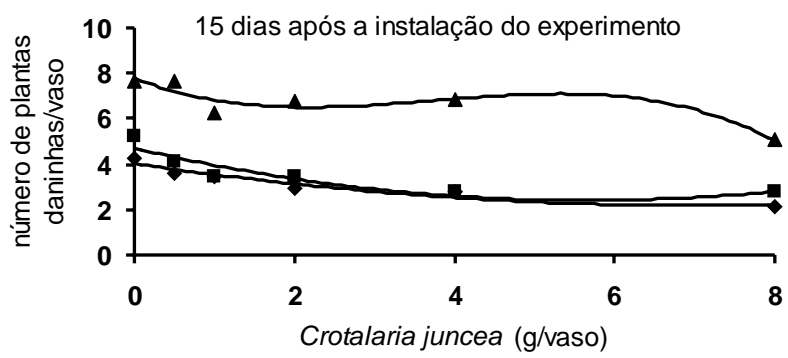
- Brachiaria decumbens
$R^{2}=0,929$
- Panicum maximum
$R^{2}=0,8518$
$\Delta$ Bidens pilosa
$R^{2}=0,8705$

Figura 6 - Número de plantas daninhas por vaso, em função do adubo verde incorporado ao solo (Piracicaba, 2000).

Analisando as Figuras 5 a 7, primeira avaliação de densidade das plantas daninhas, verifica-se que, com o aumento da quantidade de fitomassa, houve redução da densidade das plantas daninhas e que os três adubos verdes reduziram com eficiência a densidade das três espécies de plantas daninhas. Na Figura 6, observa-se que, na quantidade $4 \mathrm{x}$, a Crotalaria juncea aumentou a densidade de picão-preto, sendo esta novamente reduzida na quantidade 8x, demonstrando a correlação linear existente entre a quantidade de fitomassa e a redução da infestação por plantas daninhas, comprovada por Almeida \& Rodrigues (1985).

Os resultados da primeira e da segunda avaliação de massa seca das plantas daninhas, bem como o da segunda avaliação de densidade, quando o adubo verde foi incorporado ao solo, foram semelhantes ao da primeira avaliação de densidade, apresentando linhas de tendência bastante semelhantes (figuras não apresentadas no trabalho).

Em relação aos resultados obtidos pela utilização da quantidade de fitomassa de cada adubo verde em cada planta daninha, verificouse que, nas duas características de avaliação, ocorreram diferenças significativas, ou seja, as três leguminosas utilizadas provocaram efeitos distintos na redução da densidade e da produção de biomassa seca das plantas daninhas.

Assim, pode-se concluir que as leguminosas testadas reduziram a germinação e produção de fitomassa seca das plantas daninhas em estudo, sendo o efeito das diferentes quantidades de fitomassa maior na planta daninha $B$. pilosa, e que tanto B. decumbens como $P$. maximum são afetados de forma semelhante pelos diferentes tipos de fitomassa, provavelmente por pertencerem à mesma família (Gramineae). O adubo verde C. cajan foi o mais eficiente na redução da germinação e produção de fitomassa seca de todas as plantas daninhas estudadas, e o A. pintoi, o menos eficiente.

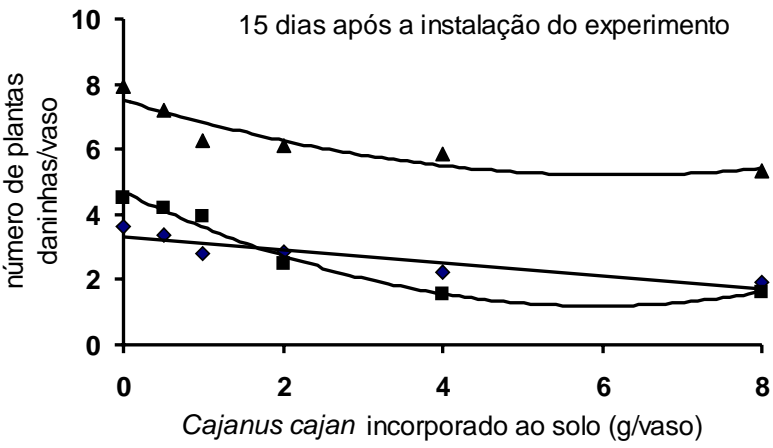
- Brachiaria decumbens
$R^{2}=0,8284$
- Panicum maximum
$R^{2}=0,9769$
$\Delta$ Bidens pilosa
$R^{2}=0,844$

Figura 7 - Número de plantas daninhas por vaso, em função do adubo verde incorporado ao solo (Piracicaba, 2000).

Planta Daninha, Viçosa-MG, v.19, n.2, p.223-228, 2001 


\section{LITERATURA CITADA}

ALMEIDA, F.S.; RODRIGUES, B.N. Guia de herbicidas: recomendações para uso em plantio direto e convencional. Londrina: IAPAR, 1985. 468p.

ALMEIDA, F.S. Controle de plantas daninhas em plantio direto. Londrina: 1991. 33p. (Circular IAPAR, 67)

BULISANI, E.A.; BRAGA, N.R.; ROSTON, A.J. Utilização de leguminosas como cobertura de solo em sistemas de adubação verde ou rotação de culturas. In: Encontro Paulista de Plantio Direto. Piracicaba: USP/ESALQ, 1987. p.63-70.

CHANCELLOR, R.J. Dormancy. In: CONFERENCE OF SEED AND ENVIRONMENT, 1979, Harven. Proceedings... Harven: 1980. p.86-105.

CHANCELLOR, R.J. Dormancy in weed seeds. Outlook Agric., v.11, n.2, p.87-93, 1982.

CHRISTOFFOLETI, P.J. Controle de Brachiaria decumbens Stapf e de Cyperus rotundus $L$. em área de cana-de-açúcar (Saccharum spp) através da técnica de rotação com amendoim (Arachis hypogaea L.) integrada ao uso de herbicidas. Piracicaba: ESALQ, 1988. 117p. Tese (Mestrado) - Escola Superior de Agricultura "Luiz de Queiroz", 1988.

COLEMAN, R.G. Perennial peanuts - potential looms larger in citrus. Citrus Ind., p.43-44, 1995.

IGUE, K. Dinâmica da matéria orgânica e seus efeitos nas propriedades do solo. In: Adubação verde no Brasil. Campinas: Fundação Cargill, 1984. p.232-267.
MIYASAKA, S. Histórico do estudo de adubação verde, leguminosas viáveis e suas características. In: FUNDAÇÃO CARGIL. Adubação verde no Brasil. Campinas: 1984, p.64-123.

MOLISH, H. Der einfluss einer pflanze auf die andere-allelopathie. Jena: Gustav Fisher, 1937. 106p.

PIAMONTE, R.P. Seminário sobre novas tendências de manejo do solo: húmus e microorganismos. São Paulo: Instituto de Cooperativismo e Associativismo. CATI/SAA, 1996. 63p.

POPEY, A.I. Factors involved in dormancy and germination of Capsella bursa-pastoris (L.) Medik. and Senecio vulgaris L. Afric. Agric. For. J ., v.41, p.304, 1976.

PRIMAVESI, A.M. Solo/Adubação verde. R. Guia Rural, n.4, p.38-44, 1986.

PUTNAM, A.R.; DUKE, W.D. Biological suppression of weeds: evidence of allelophaty in accessions of cucumber. Science, v.185, p.370-372.1974.

SWAIN, T. Secondary compounds as protective agents. Ann. Rev. Plant Physiol., v.23, n.2, p.479-501, 1977.

TEASDALE, J.R. Cover crops, smother plants, and weed management. New York: Arbor Press, 1998. p.247-270.

VOGTMANN, H.; WAGNER, R. Agricultura ecológica - Teoria \& Prática. Porto Alegre: Mercado Aberto, 1987. 168p.

WALKER, R.H.; BUCHANAN, G.A. Crop manipulation in integrated weed management systems. Weed Sci., v.30, n.51, p.17-24, 1982. 